\title{
DDA Simulations of Large Flume Tests and Large Landslides Triggered by the Wenchuan Earthquake
}

\author{
Qingqing Yang1, Zhiman $\mathrm{Su}^{2}$, Fei Cai ${ }^{3}$ \\ ${ }^{1}$ Faculty of Geosciences and Environmental Engineering, Southwest Jiaotong University, Chengdu, China \\ ${ }^{2}$ Institute of Mountain Hazards and Environment, Chengdu, China \\ ${ }^{3}$ Department of Environmental and Engineering Science, Gunma University, Kiryu, Japan \\ Email: yangqq 71@126.com
}

Received March 2014

\section{Abstract}

This paper presents some numerical simulations using Discontinuous Deformation Analysis (DDA). First, DDA was applied to reproduce a series of granular flows released in a large flume. The comparison between simulated velocity and that measured in the tests demonstrates the effectiveness of DDA on description of kinematic behavior of blocky assembly. Simulated results were highly sensitive to the shape and angularity of blocky elements. Employing unrealistic block might result in different behavior from real situation. Second, three large landslides triggered by the Wenchuan earthquake were simulated. A well agreement with field data was obtained if apparent friction coefficient determined by post-analysis was adopted.

\section{Keywords}

\section{Discontinuous Deformation Analysis, Flume Test, Lansdslide}

\section{Introduction}

Discontinuous Deformation Analysis (DDA) is one of most popular discrete element methods for discontinuous rock mass. DDA, which was originally formulated by Shi [1], forms a system of algebraic equations based on the principle of minimum potential energy and uses displacements as variables in an implicit formulation. Though DDA was developed during the late 1980s, and is thus a relatively new numerical simulation tool, it has been applied to a wide range of problems, and researchers in the DDA community have dedicated a great deal of effort to document the accuracy of this method by performing validation studies.

\section{DDA Simulations of Large Flume Tests}

A detailed description about the large flume tests was presented in Yang et al. [2]. The large flume consists of an upper slope $5.5 \mathrm{~m}$ long and inclined at $45^{\circ}$ connected to a lower slope $10.0 \mathrm{~m}$ long and inclined at $10^{\circ}$. Table 1 shows the varied test conditions. 
Table 1. Summary of large flume tests.

\begin{tabular}{ccccccccc}
\hline & & \multicolumn{6}{c}{ Released materials } \\
\cline { 4 - 6 } Case No. & Test conditions & Initial & geometry & & Cubes $[\mathrm{kg}]$ & Cobbles $[\mathrm{kg}]$ & Gravel & Total mass \\
\cline { 4 - 6 } & & & Large & Small & Large & Small & {$[\mathrm{kg}]$} & {$[\mathrm{kg}]$} \\
\hline 2 & Matting & Triangle & 200 & 200 & 0 & 0 & 0 & 400 \\
3 & Matting & Triangle & 0 & 0 & 0 & 0 & 400 & 400 \\
4 & Matting & Triangle & 200 & 200 & 0 & 0 & 400 & 800 \\
10 & Matting & Triangle & 0 & 0 & 200 & 200 & 0 & 400 \\
14 & Matting & Triangle & 0 & 0 & 200 & 200 & 400 & 800 \\
\hline
\end{tabular}

The geometry and initial configuration of the numerical model were based on a $2 \mathrm{D}$ reproduction of the experimental conditions. The effect of the flume's sidewalls was not taken into account because their roughness was sufficiently small to ensure the flow in 2D conditions. The shear strength of the materials was measured by the large-scale direct shear tests [2]. The joints were assumed with zero tensile strength. The numerical control parameters were as follows: the time step size $=0.001 \mathrm{~s}$, the maximum allowed displacement ratio $=0.00085$, the contact spring stiffness $=1 \times 10^{6} \mathrm{kN} / \mathrm{m}$.

\subsection{Mono-Materials}

Figure 1 illustrates the initial arrangement of granular elements for DDA simulations for case 2 (400 $\mathrm{kg}$ cubes), case 3 (400 kg gravel), and case 10 (400 kg cobbles).

Figure 2(a) shows that the trend of the simulated velocities corresponded well with that of the measured velocities in case 2. Both the simulated and measured velocities fluctuated due to the propulsion of subsequent particles to the slowed front by impact. This confirmed the conclusion that continuous collisions among particles are partly responsible for the high mobility and long run-out of rock avalanches [2]. DDA accurately reflected this important phenomenon of continuous collisions.

A total of 178 irregular quadrangles were generated randomly to simulate the gravel in case 3 . The simulated velocity agreed with the measured one (Figure 2(b)).

Figure 2(c) also shows that DDA accurately predicted the velocity of the cobbles in case 10. Furthermore, the cobbles were also simulated by regular octagons. The simulated velocity of the regular octagon was much higher than that of the hexagon, and also much higher than the velocity measured in the tests. A majority of the octagonal blocks moved beyond the flume and stopped on the horizon; this was significantly different from the situation occurred in the tests. Thus, the velocity and run-out were highly sensitive to the shape and angularity of the granular elements in the numerical analysis. This conclusion corresponded with that drawn by other researchers [3], who found that the DDA simulation results are extremely sensitive to computed meshes. Therefore, the shape and angularity of the blocks had to be determined carefully in the numerical model because the use of unrealistic granular elements may cause the grain behavior to be modeled inaccurately.

\subsection{Composites}

Figure 3 shows that two composites were initially arranged as alternating layers of blocks and gravel (a composite of $400 \mathrm{~kg}$ cubes and $400 \mathrm{~kg}$ gravel in case 4, and a composite of $400 \mathrm{~kg}$ cobbles and $400 \mathrm{~kg}$ gravel in case 14). A total of 68 cubes in case 4 and 105 cobbles in case 14 were arranged at the positions as close as possible to those in the tests.

DDA accurately predicted low velocities of the composite of cubes and gravel in case 4 (Figure 4(a)), comparing with the cube and gravel mono-materials with small volumes (cases 2 and 3). The agreement between the simulation and experiment indicates that the energy dissipation caused by friction between the gravel and cubes was modeled accurately by DDA.

DDA also accurately predicted an unexpectedly high velocity of the composite of cobbles and gravel in case 14 (Figure 4(b)), almost the same as those for the cobble and gravel mono-materials. However, the simulated 


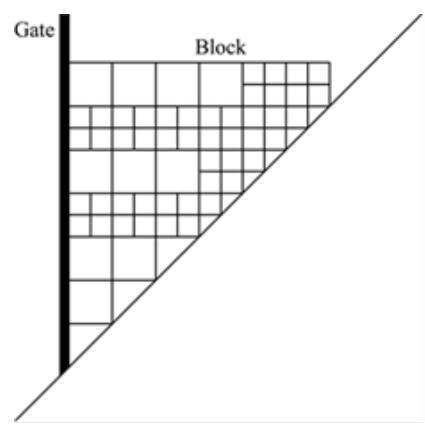

(a)

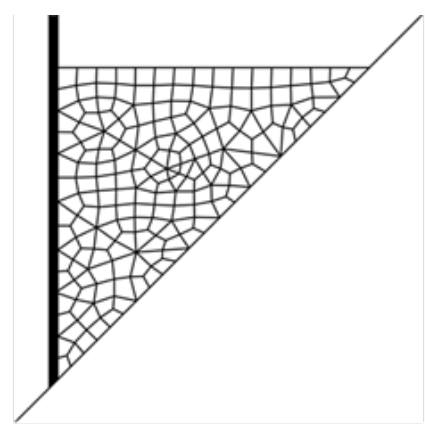

(b)

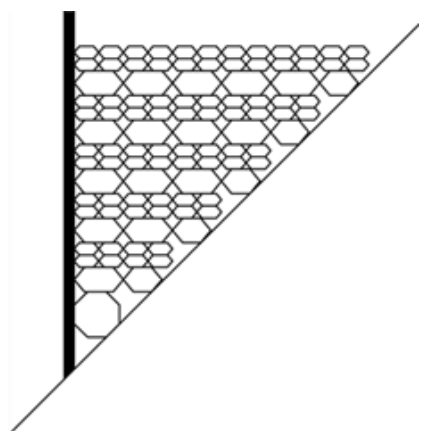

(c)

Figure 1. Initial geometry of the blocks in Cases 2, 3, and 10. (a) Case 2; (b) Case 3; (c) Case 10.

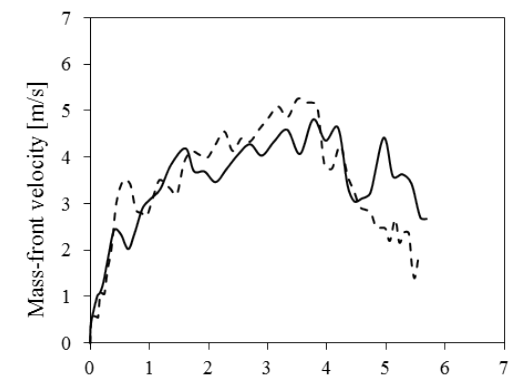

(a)

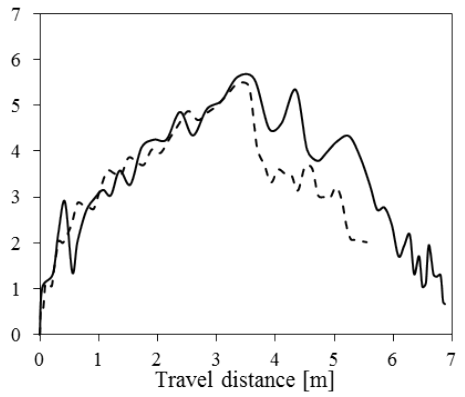

(b)

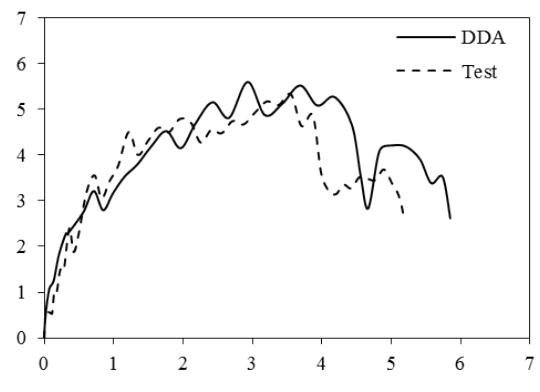

(c)

Figure 2. Simulated and measured velocities of mono-materials in Cases 2, 3, and 10. (a) Case 2; (b) Case 3; (c) Case 10.

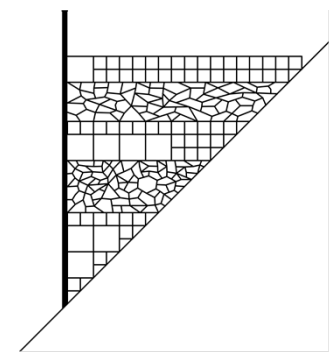

(a)

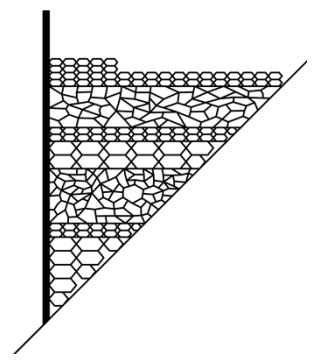

(b)

Figure 3. Initial geometry of the blocks in Cases 4 and 14. (a) Case 4; (b) Case 14.

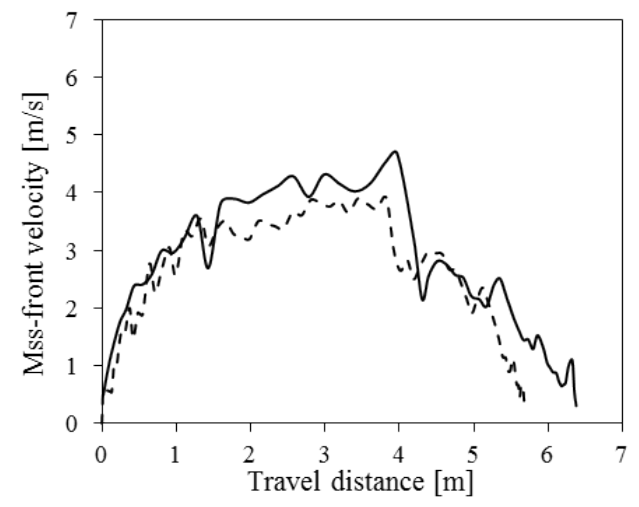

(a)

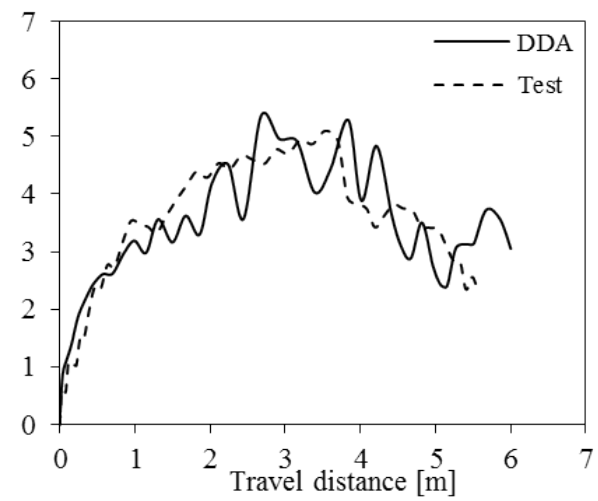

(b)

Figure 4. Simulated and measured velocities of composites in Cases 4 and 14. (a) Case 4; (b) Case 14. 
velocity fluctuated more because the DDA in this study did not take the energy loss caused by the collision among particles and the collision between particles and the flume into account. Thus, the velocity of the frontal particles increased more significantly when subsequent high-velocity particles provided propulsion to allow them to accelerate. Collisions frequently occurred and considerably dissipated the energy. A restitution coefficient should be introduced to consider the energy loss caused by the collisions. Ma et al. [4] proposed a modified DDA method by introducing a restitution coefficient to account for the energy loss caused by the collisions when simulating rock-fall. They found that the velocity of rock-falls is most accurately simulated using a restitution coefficient of 0.7. Unfortunately, the restitution coefficient was not introduced in DDA program used in this study.

\section{DDA Simulations of Large Landslides}

\subsection{The Donghekou Landslide}

The Donghekou landslide-debris flow is a typical rapid, long run-out, compound landslide with the height difference between the toe and main scarp of $540 \mathrm{~m}$, a sliding distance of $2270 \mathrm{~m}$, and a volume of 15 million $\mathrm{m}^{3}$ [5]. This landslide buried seven villages and and killed 780 people, and it dammed two confluent rivers forming a massive lake. It is composed of sandstone, shale, and schist of Cambrian age and is located about $4 \mathrm{~km}$ from the active fault-rupture trace.

The main numerical control parameters of DDA simulation are as follows: the time step size $=0.01 \mathrm{~s}$, the maximum allowed displacement ratio $=0.0015$, the contact spring stiffness $=5 \times 10^{8} \mathrm{kN} / \mathrm{m}$, and the factor of over-relaxation $=1.3$.

The deposit, calculated using the friction angle of about $35^{\circ}$, measured in laboratory, was combined with the actual final deposit observed in the field, as illustrated in Figure 5. The sliding mass remained in approximately the same place at $200 \mathrm{~s}(20,000$ time steps) after the inception of motion. The calculated run-out was much shorter than the actual run-out. The trial calculations show that simulation results were significantly affected by friction coefficient. The friction coefficient measured in the laboratory was difficult to reproduce the extremely long run-out of the rock avalanche. This implies that the 'size effect' should be considered in the simulation of field events.

For the Donghekou landslide, the apparent friction coefficient was 0.238 [5]. When the apparent friction coefficient was used, the calculated deposit corresponded well with the actual deposit (Figure 6). Whether the apparent friction coefficient can be served as a reasonable parameter in reproducing the actual deposit of field rock avalanches will be further confirmed by other two large landslides also triggered by the Wenchuan earthquake.

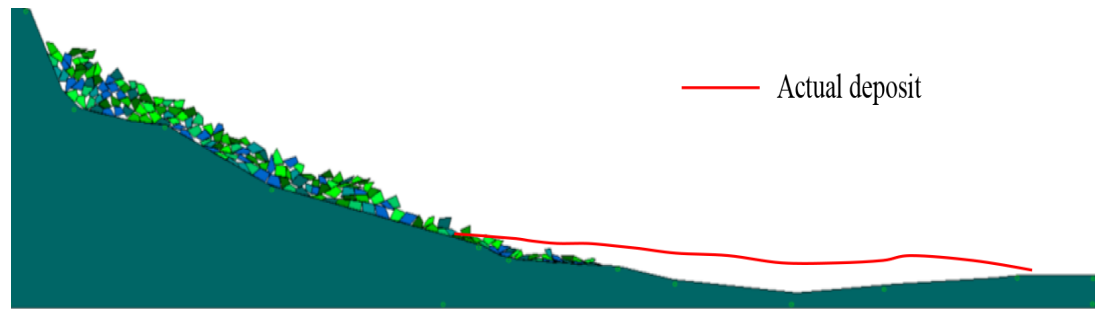

Figure 5. Calculated final deposit of the Donghekou landslide when the measured friction coefficient was used.

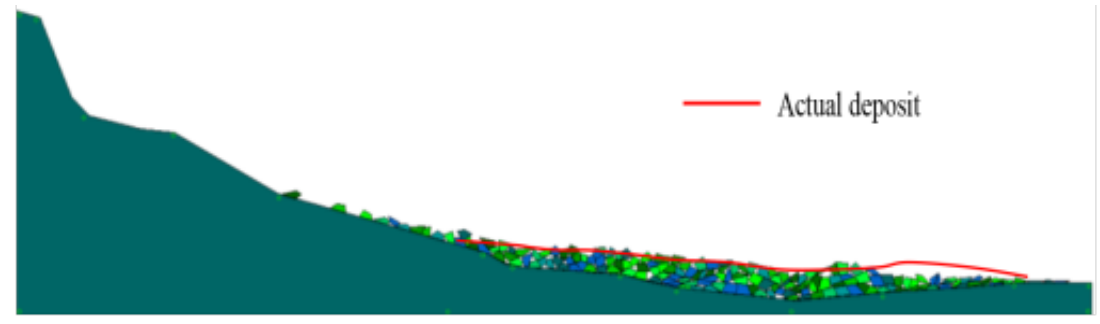

Figure 6. Calculated final deposit of the Donghekou landslide when the apparent friction coefficient was used. 


\subsection{The Xinbei Middle School Landslide}

The Xinbei Middle School landslide reactivated by the Wenchuan earthquake, its geologic components consisting of thick limestone of upper Devonian and lower Carboniferous Periods. It has a length of $560 \mathrm{~m}$, a width of $200 \mathrm{~m}$, an average thickness of $20 \mathrm{~m}$, a maximum thickness of $40 \mathrm{~m}$, a height difference of $300 \mathrm{~m}$, and a volume of 2.4 million $\mathrm{m}^{3}$. Among the displaced sliding mass, there are huge blocks with maximum single-block volumes of $1000 \mathrm{~m}^{3}$. The huge blocks destroyed a three-story building and several adjacent houses. About 700 people were killed by this landslide. At the toe part of the landslide deposit, upheaval occurred at the ground surface along the main street, which was thought to be related to the thrust scarp resulting from movement on the earthquake fault.

The main numerical control parameters necessary for DDA were the same as those used for the simulation of the Donghekou rock avalanche. The apparent friction coefficient of this landslide was 0.625 . The calculated deposit was combined with the actual final deposit observed in the field, as illustrated in Figure 7. The calculated deposit was consistent with the actual deposit for the Xinbei Middle School landslide.

\subsection{The Shibangou Landslide}

The Shibangou landslide was $815 \mathrm{~m}$ long, $790 \mathrm{~m}$ wide, an average thickness of $15 \mathrm{~m}$, a maximum thickness of $50 \mathrm{~m}$, a height difference of $240 \mathrm{~m}$, and a volume of 4.5 million $\mathrm{m}^{3}$. More than 200 people were killed by this landslide. It dammed the Qingzhujiang river forming a massive lake with a maximum reservoir capacity of 11 million $\mathrm{m}^{3}$.

The main numerical control parameters of DDA were the same as those used for the simulation of the Donghekou rock avalanche. The apparent friction coefficient of 0.268 was used for the Shibangou landslide.

Figure 8 shows that the calculated deposit agreed well with the actual deposit observed in the field for the Shibangou landslide.

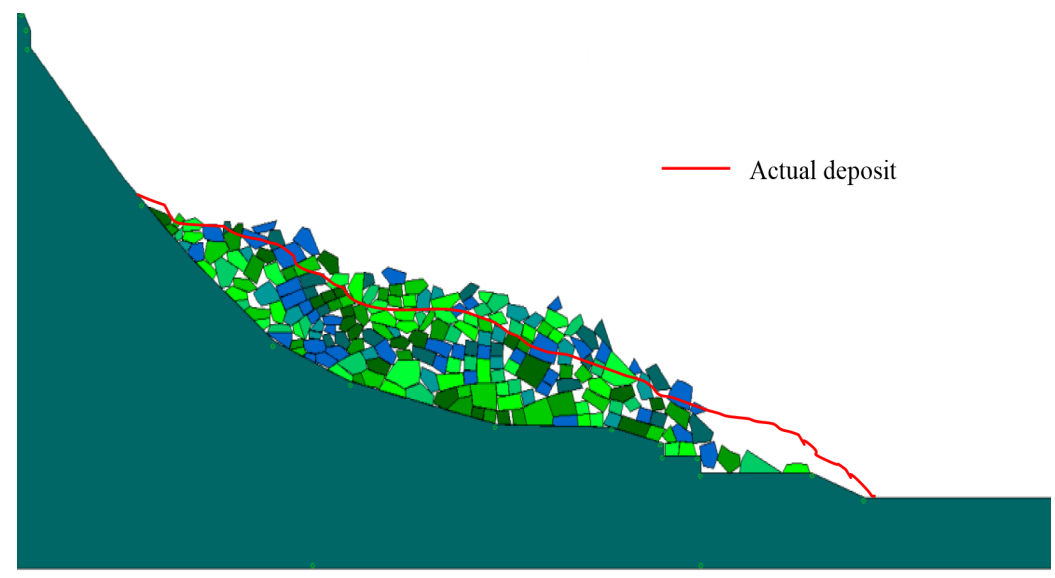

Figure 7. Calculated final deposit of the Xinbei Middle School landslide when apparent friction coefficient was used.

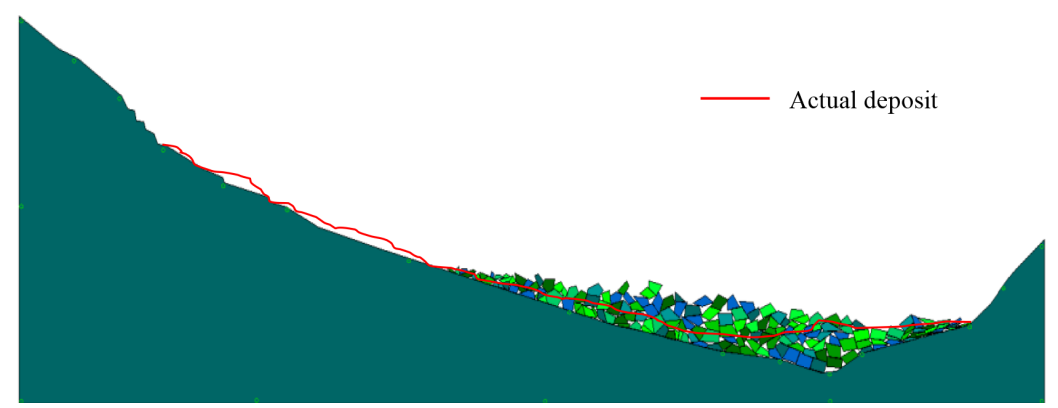

Figure 8. Calculated final deposit of the Shibangou landslide when apparent friction coefficient was used. 


\section{Conclusions}

In this paper, the large flume tests and three large landslides triggered by the Wenchuan earthquake were reproduced by DDA, and the following conclusions to be obtained.

(1) DDA was capable of giving considerably satisfactory simulations of the large flume tests, and the differences between the simulations and measurements were limited to an acceptable range. This consistency demonstrates that DDA effectively described the kinematic behavior, material characteristics, and topographic constraint of granular flows in the large flume tests.

(2) Both the simulated and measured velocities in the large flume tests fluctuated due to the propulsion of subsequent particles to the slowed front by impact. DDA accurately reflected this important phenomenon of the continuous collision among particles, which was partly responsible for the high mobility and long run-out of rock avalanches.

(3) The simulated results were highly sensitive to the shape and angularity of granular elements; thus, employing realistic elements was important for predicting the behavior of granular flows in real situations.

(4) DDA also accurately predicted low velocities of the composite of cubes and gravel, and the agreement between the simulation and experiment indicates that DDA accurately modeled the energy dissipation caused by the friction among particles.

(5) Simulation results show that friction coefficient strongly influenced final deposits of large events. The calculated deposit was only similar to the actual deposit when the apparent friction coefficient, which was determined by field investigation, was used rather than the friction coefficient measured in the laboratory.

\section{References}

[1] Shi, G.H. (1988) Discontinuous Deformation Analysis. Ph.D. Thesis, University of California, Berkeley.

[2] Yang, Q.Q., Cai, F., Ugai, K., Yamada, M., Su, Z.M., Ahmed, A., Huang, R.Q. and Xu, Q. (2011) Some Factors Affecting Mass-Front Velocity of Rapid Dry Granular Flows in a Large Flume. Engineering Geology, 122, $249-260$. http://dx.doi.org/10.1016/j.enggeo.2011.06.006

[3] Chen, G.Q., Zheng, L., Zhang, Y.B. and Wu, J. (2013) Numerical Simulation in Rockfall Analysis: A Close Comparison of 2-D and 3-D DDA. Rock Mechanics and Rock Engineering, 46, 527-541. http://dx.doi.org/10.1007/s00603-012-0360-9

[4] Ma, G.C., Matsuyama, H., Nishiyama, S. and Ohnishi, Y. (2011) Practical Studies on Rockfall Simulation by DDA. Journal of Rock Mechanics and Geotechnical Engineering, 3, 57-63. http://dx.doi.org/10.1007/s00603-012-0360-9

[5] Xu, Q., Pei, X. and Huang, R.Q. (2010) Large-Scale Landslides Induced by the Wenchuan Earthquake. Chinese Science Press, Beijing, 408-422 (in Chinese). 